\title{
Causes and Control of Dynamic Audit Expectation Gap
}

\author{
Xiu-e Yuan, Ying Liu \\ Department of Economics and Administration, North China Electric Power University, Baoding, China
}

\begin{abstract}
The current audit expectation gap growing trend has been a threat to the development of the audit profession, in-depth study of the audit expectation gap causes, and its effective control is imminent. This article from the three aspects, analyzes the audit expectation gap causes, and some suggestions to control its validity.

Keywords - Audit audit expectation gap; public; auditors

\section{Introduction}

Since the emergence of the audit of the audit expectation gap had been in existence, but with the development of market economy, the business of the complex, the audit expectation gap between market demand dislocation, the audit expectation gap is getting bigger and bigger. Since the existence of the audit expectation gap has been affecting the audit, the audit profession, so more and more magnified audit expectation gap on the audit industry had serious adverse effects, even begun to threaten the existence and development of the audit profession. So that to strengthen the research on audit expectation gap without delay.
\end{abstract}

\section{What is the "Audit Expectation Gap"}

Although the audit expectation gap that appeared since the audit has been there, but so far theorists did not form a unified "audit expectation gap" concept. This article will audit expectation gap understood as: audit expectation gap refers to the gap between the needs of the public audit and the audit objectives and the actual audit between including both the public due to wrong perception, but also the lack of capacity of the CPA forming a gap. [1]

\section{The Audit Expectation Gap Factors}

The reason the audit expectation gap produced varied, but it is mainly attributed to the following three areas.

\section{A. Public Social}

\section{1) The Public's Misperception of Audit Practice}

Public audit practice of cognitive errors are many, the first point is that the public is lack of expertise in auditing their wishful thinking audit opinion must be correct, the auditor can identify companies that may exist for them all operating errors and shortcomings.

Another public perception audit practice bug is their high expectations of the audit. Them as decision-makers, whose decisions are focused on the future, and asked to make the decision to include all aspects, and the audit is to make the audit opinion based business has already occurred, apparently not fully meet the various needs of the public a. They want to be able to audit the risks, uncertainties, and other information the opportunity to perform forensic and promptly informed of the situation is difficult to continue to operate the company, which already has predicted the nature of the requirements, while forecasting the uncertain properties.

2) "Deep Pocket" Theory Phenomenon

Affected by this theory, the public in the use of audited financial statements to make decisions, once their decisions failure by the loss, even knowing that the auditor is not at fault, it is still to the courts in the hope that the auditors who receive compensation, compensate for the loss, and even lawsuits failed, they would not have any losses. The accounting firm is to avoid the huge legal fees and litigation brought them negative social impact from the litigation brought them, such as reputation damage, etc., methods of-court settlement of most of the take. This negative attitude of the public to deal with unethical behavior undoubtedly contributed to the expansion of the public responsibility of the auditors in accordance with the wishes of their own bad atmosphere, then, requires the public on audit practice of getting high, but auditors can not meet, thus expanding the audit expectation gap. [2]

\section{B. Auditors Aspect \\ 1) The limited capacity of auditors themselves}

They have strictly follow the principle of audit reports carried out carefully and thoroughly reviewed, but due to lack of their own ability, not fully respond to this increasingly complex business transactions, which led to biased audit opinion on the cause of the stakeholders certain loss. As a result, it led to the formation of the audit expectation gap.

2) Lack of Professional Ethics of Auditors

CPA professional ethics required in the implementation of the business must maintain integrity, objectivity, honesty and a series of principles, But trade associations and our law to break the law for serious audit practice of penalties is relatively weak,this way, one is a huge temptation, one is low and the cost of having a fluke of the law, so that auditors caught "moral crisis."[3]

C. Aspects of The Auditing Profession

1) Defects Audit Theoretical Level Lag and Audit

Techniques

The level of development of auditing theory is to chase the development of the market economy and the public demand for audit continues to improve, so there is the inevitable lag. The market economy has become increasingly made complicated, the public demand for increasingly higher audit, but the audit to improve the theoretical level, but can not

This work is partially supported by NSF Grant \#2003168 to H. Simpson and CNSF Grant \#9972988 to Miss. Yuan 
do the same time, it depends on the discussion of theoretical research and practical research staff, which is consuming a lot of time.

\section{2) Exist in the Form of Certified Public Accountants and CPA Unreasonable}

While the independence of the accounting firm, that it is neither affiliated companies are not affiliated with government control, and it has been a way for stakeholders to review the company's financial reporting, and corporate financial reporting issue really fair the audit opinion services exist. But at the same accounting firm is profitable organization, a forprofit, organization chase how to maximize the benefits it can do to serve the public?

\section{3) Irrational Employment Structure of CPA}

Certified Public Accountants for the public service is to disclose a company's financial reports for the public, but it employed by the company's managers, coupled with the aforementioned accounting firm profitability, which is to make the accountant the firm has been greatly hampered when tradeoffs. Aims and purposes of the accounting firm is marketoriented, customer-centric, and its customers is the company's operators, managers.[4]It is worth mentioning that the management of more concern is not the level of service quality audit, but auditors whether the type of the audit report and the auditors issued an unqualified audit opinion. As a result, the accounting firm's audit quality service can not be guaranteed, it makes the audit expectation gap generated.

\section{4) Accountability and Audit Unclear Division of}

\section{Responsibilities}

In the current audit model, when significant audit events, people tend to fault attributed to the CPA's audit responsibilities, while ignoring precisely because of unreasonable accounting that led to the final result of the operation. It can be said, in the case of audit failure, accountability is the ultimate cause, but the audit only the direct cause of this error condition. So I have to admit responsibility division of accountability and audit is one of the reasons unclear gap generated audit.

\section{Recemmendation of controling audit expectation gap}

Several motives based on the above analysis of the audit expectation gap, we propose the following recommendations to control the audit expectation gap.

\section{A. Guide Public Audit Expectations Reasonably}

This paper argues that to strengthen the public about its auditing and reporting of knowledge, so that the formation of the correct public perception of the audit, rather than their subjective. They recognized the need to have: (1) Auditing lag exists, not that they need a new audit practice will be able to immediately meet their requirements; (2) auditors issued an audit opinion is based on objective facts existed in the past, and can not guarantee future business prospects are immutable, so the public in making decisions still need more time to consider and ponder; (3) Although the company's auditors have conducted a thorough review of the financial statements in the course of carrying out the review of the program, but because
Defects such as auditing techniques, as well as high-tech fraud intentionally managers, auditors and review the results did not completely guarantee error; (4) have accountability, management responsibility and audit responsibility coexist, when the company went bankrupt, not all of responsibility comes down to the responsibility of auditors.

\section{B. A reasonable division of accountability, audit responsibility and management responsibility}

Theoretical researchers should accelerate the rational division of accountability, audit responsibility and responsibility for the operation of research progress, as soon as possible to propose a reasonable classification method, so the public in distinguishing these three can evidence-based. And strengthen public education and guidance in this regard, so that they form a correct perception.

\section{Improve CPA Access Threshold, and Strengthen the CPA Continuing Education}

In China, based on a substantial income CPA, more and more people joined the queue to apply for CPA. This surge in the number of CPA candidates phenomenon in a sense, did not bring good results, on the contrary, it makes a lot of people rely on utilitarian dead reading, reading books dead way to get the note will be allowed to enter, But their actual practice ability is very limited, and this limited hands-on ability is obviously not conducive to the positive development of audit practice.

In addition, the CPA continuing education can not be underestimated. China's current economy is in a state of rapid development, the rapid development of the market economy will bring increasingly complex economic business, so they had mastered technology can not meet audit current economic and business needs. So to strengthen the continuing education of certified public accountants, with Professor of Economics changing market constantly improve their audit technology and methods and adapt to social changes. Meanwhile, in the continuing education process, we can not ignore the CPA's moral guidance.

\section{Improve the Evaluation Oversight Mechanism to Improve the Cost of Illegal Behavior \\ Our evaluation of the auditor oversight mechanisms, there} are many disadvantages, should take effective measures to be amended. In addition, to strengthen the CPA's government supervision, social supervision and oversight within the industry, you can take the "who report who prize" approach to stimulate public enthusiasm.

Compared to the irregularities, illegal acts can benefit, illegal auditors, violations of costs are low, so that auditors weigh violations, illegal and illegal profits when costs tend to choose easy misconduct adventure. So its important to improve auditors violations, illegal cost.

\section{E. Strengthen Auditing Theory Research Progress}

Strengthen auditing theory research progress, so that audit practice can be closer to the needs of a modern market, promote the improvement of audit quality service auditors, the 
entire audit sector has emerged as a good positive status, and thus to the public but also the role of the audit profession form a good evaluation. Strengthening the role of audit theory research progress is evident.

\section{F. Adjust the Accounting Firm Service Model}

Contradictions between the accounting firm's profitability and service agency, the accounting firm hired managers played in the public sector have hindered the development of audit, so this perceived need to seek a reasonable and suitable for the development of audit CPA service mode. If the accounting firm for the appointment and dismissal of the power placed in the hands of the shareholders of listed companies will be more beneficial if the objective of the audited entity and auditors impartial audit practice it?

\section{Conclusion}

Expanded audit expectation gap exists and audit practice to bring a huge challenge, repeated audit failures makes the reputation of the entire auditing profession seriously damaged, we must take the necessary measures to control the expanded audit gaps. In-depth analysis and reporting audit expectation gap and expand the reasons, so that the public and audit practitioners or other persons associated with the audit profession can understand, to regulate the practice of environmental auditing, practicing order is everyone to action, Not only is the obligation of auditors. Some of this article's recommendations may be simply personal vision or a little superficial, some difficulty, but only if there is a reasonable idea of the situation, an effort to provide direction for researchers and implementers in implementation.

\section{References}

[1] Hua Yong. audit expectation gap. Business Modernization. October 2007.

[2] Li Xue; Zhang Fan. To investigate the causes of the audit expectation gap and correcting the path of. Nanjing University of Finance and Economics. July 2011.

[3] Zhu Wei. Study elements of the audit expectation gap and narrow Countermeasure. Zhejiang Industry and Commerce University. December 2012.

[4] Lv Hui. Several questions about the audit expectation gap analysis . Dongbei University of Finance. December 2007. 